\title{
Pain Management in Total Knee Artroplasty: Local Periarticular Injection
}

\author{
Mahmut Tuncez (Corresponding author) \\ Department of Orthopedics and Traumatology, Izmir Katip Celebi University Ataturk Training and \\ Research Hospital, Izmir, Turkey \\ E-mail: drmahmuttuncez@gmail.com \\ Suleyman Sofulu \\ Department of Orthopedics and Traumatology, Izmir Katip Celebi University Ataturk Training and \\ Research Hospital, Izmir, Turkey \\ Mehmet Maden \\ Department of Orthopedics and Traumatology, Izmir Katip Celebi University Ataturk Training and \\ Research Hospital, Izmir, Turkey \\ E-mail: mhmtmdn@gmail.com \\ Cemal Kazimoglu \\ Department of Orthopedics and Traumatology, Izmir Katip Celebi University Ataturk Training and \\ Research Hospital, Izmir, Turkey \\ E-mail: ckazimoglu2000@gmail.com
}

\section{Declaration of interest: The authors report no declarations of interest}

Funding: There is no funding source.

\begin{abstract}
Objective: Pain that occurs in the early period after total knee arthroplasty (TKA) operation decreases patient comfort and affects rehabilitation. For this reason, various methods are used to reduce pain after surgery. Our aim in this study is to compare the local periarticular injection (LPE) regimen applied during surgery with the classical analgesic regimen.
\end{abstract}

Patients and methods: 124 patients who underwent arthroplasty due to primary gonarthrosis were included in our study. The classical analgesic regimen (oral or iv nsaii / opioid) was performed in 54 patients, and local periarticular injection (intraoperative morphine-diclofenac-adrenaline-bupivacaine cocktail) was performed in 70 patients and compared as a backward cohort. Patients examined for preop and postop 6th Hour, 12th Hour, 24th Hour, 48th Hour, 72th Hour and 15th Day 30th Day visual pain scale (VAS), flexion-extension degree, oral and parenteral drug use, postop bleeding and complications. Those with bilateral TKA, those with chronic liver disease, those with chronic kidney disease, all revision TKAs were not included in the study.

Results: There was no statistically significant difference between age, body mass index, length of stay, walker release and blood transfusion values between the two groups ( $p>0.05)$. Postoperative 6th and 12 th hours, postoperative 1st and 2nd day VAS scores, hemovac drain bleeding amount, postoperative NSAID, acetaminophen and Opioid use were found to be statistically significantly lower in patients undergoing LPE $(\mathrm{p}<0.05)$. There was no statistically significant difference between the groups in terms of postoperative 3-15-30th Day VAS values $(p>0.05)$. In addition, the postoperative $1 \mathrm{st}$ and 15 th flexion values were found to be statistically significantly higher in those who underwent $\operatorname{LPE}(\mathrm{p}<0.05)$. There was no significant difference between the two groups in terms of other data and complications.

Conclusion: Although the number of drugs in the cocktail we use in our study is low compared to similar studies in the literature, its effectiveness was found similar and significant with other studies. As a result, local periarticular injection is a highly effective and applicable method for early rehabilitation, pain control and bleeding control after total knee arthroplasty.

Keywords: local periarticular enjection, total knee arthroplasty, pain 
Special Issue of Health Sciences

DOI: $10.7176 / \mathrm{JSTR} / 6-03-40$

\section{Total Diz Artroplastisinde Ağrı Yönetimi: Lokal Periartiküler Enjeksiyon}

Özet:

Giriş: Total diz artroplastisi (TDA) erken dönemde ortaya çıkan ağrı hem hasta konforunu düşürmekte ve rehabilitasyonu etkilemektedir. Bu nedenle ameliyat sonrası ağrıyı azaltmak için çeşitli yöntemler kullanılmaktadır. Bu çalışmadaki amacımız ameliyat sırasında uygulanan lokal periartiküler enjeksiyon (LPE) rejimini klasik analjezik rejim ile karşılaştırmaktır.

Materyal Metod: Primer gonartroz nedeniyle artroplasti uyguladığımız 124 hasta çalışmamıza dahil edildi. 54 hastaya klasik analjezik rejim ( ameliyat sonrası oral yada iv nsaii/opioid ), 70 hastaya lokal periartiküler enjeksiyon (intraoperatif morfin-diklofenak-adrenalin-bupivakain kokteyli ) yapılarak geriye dönük kohort olarak karşılaştırıldı. Hastalar; preop ve postop 6. Saat, 12. Saat, 24. Saat, 48. Saat, 72. Saat ve 15. Gün 30. Gün olmak üzere visüel analog ağrı skalası (VAS), fleksiyon- ekstansiyon derecesi, oral ve parenteral ilaç kullanımı, postop kanama ve komplikasyonlar açısından incelendi. Bilateral TDA yapılanlar, kronik karaciğer hastalığı olanlar, kronik böbrek hastalığı olanlar, tüm revizyon TDA' lar çalışmaya dahil edilmedi.

Bulgular: Her iki grup arasında yaş, vücut kitle indexi, yatış süreleri, yürüteç bırakma ve kan TX değerleri arasında istatistiksel olarak anlamlı fark bulunmadı $(p>0,05)$. LPE uygulanan olguların postop 6. ve 12. saat, postop 1. ve 2. gün VAS skorları, hemovak dren kanama miktarı, ameliyat sonrası NSAIII, asetaminofen ve Opioid kullanım miktarları LPE uygulanmayan olguların değerlerinden istatistiksel olarak anlamlı düşük bulundu $(\mathrm{p}<0,05)$. Postoperatif 3-15-30. Gün VAS değerleri açısından gruplar arasında istatistiksel olarak anlamlı fark bulunmadı $(\mathrm{p}>0,05)$. Ayrıca LPE uygulananlarda postoperatif 1 . ve 15. gün fleksiyon değerleri istatistiksel olarak anlamlı yüksek bulundu $(\mathrm{p}<0,05)$. Diğer veriler ve komplikasyonlar açısından iki grup arasında anlamlı fark bulunmadı.

Sonuç: Çalı̧̧mamızda kullandığımız kokteylin içeriğindeki ilaç sayısı literatürdeki benzer çalışmalara kıyasla az olmakla birlikte etkinliği diğer çalışmalarla benzer ve anlamlı olarak bulunmuştur. Sonuç olarak lokal periartiküler enjeksiyon total diz artroplastisi sonrası erken rehabilitasyon, ağrı kontrolü ve kanama kontrolü için oldukça etkili ve uygulanabilir bir yöntemdir.

Anahtar kelimeler: lokal periartiküler enjeksiyon, total diz artroplastisi, ağr1

\section{Giriş}

Total diz artroplastisi (TDA) günümüzde son evre diz osteoartrozu tedavisinde oldukça yaygın uygulanan etkinliği ve güvenirliği kanıtlanmış bir yöntemdir. Diğer ortopedik operasyonlar gibi ameliyat sonrası erken dönemde (postop 48 saat) ortaya çıkan ağrı hem hasta konforunu düşürmekte ve rehabilitasyonu ve mobilizasyonu kötü yönde etkilemektedir[1]. TDA hemen sonrasında diz fleksiyon ve ekstansiyon aralığının maksimum olması için minimal ağrı ile diz eklemi mobilize edilmesi gerektiği söylenir[2][3].

TDA sonrası ortaya çıkan ağrı sorununu çözümlemek amaçlı bir çok farklı yöntem tariflenmiştir. Güncel yayınlar ve uygulamalar ameliyat sırasında uygulanan lokal anestezik uygulamasını popüler hale getirmiş olmakla beraber bu yöntemin konvansiyonel yöntemlere üstünlüğünü ortaya koyan çok fazla çalışma bulunmamaktadır. Bu çalışmadaki amacımız perop uygulanan lokal periartiküler enjeksiyon (LPE) rejimini klasik analjezik rejim ile karşılaştırmaktır. Ayrıca her iki yöntemin hasta konforu, postop rehabilitasyon ve komplikasyon gelişimi açısından karşılaştırılması amaçlanmaktadır.

\section{Materyal Metod}

Ocak 2018- Ocak 2019 arasında primer gonartroz nedeniyle artroplasti uyguladığımız 124 hasta vaka serisi olarak çalışmamıza dahil edildi. 54 hastaya konvansiyonel ağrı kontrolü, 70 hastaya LPE yapılarak retrospektif olarak karşılaştıııldı. Bilateral TDA yapılanlar, kronik karaciğer hastalı̆̆ı olanlar, kronik böbrek hastalığı olanlar, revizyon TDA' lar çalışmaya dahil edilmedi. 
Lokal periartiküler enjeksiyon için kullanılan solüsyonda; 150 cc serum fizyolojik içine ; 1 ampul morfin hidroklorür, 1 ampul diklofenak sodyum $75 \mathrm{mg} / 3 \mathrm{ml}, 1$ ampul adrenalin 0,25/1 ml , 1 ampul bupivakain hidroklörür 0,05 kullanıldı (şekil 1). Bu kokteyl operasyon sırasında tüm kemik kesiler bitince ve protez yerleştirilmeden önce uygulandı. İlk önce fleksiyonda iken femur ve tibianın tüm kemik kesi etrafindaki periosta enjekte edildi. Daha sonra femur eleve edilerek posteior kapsül ve menisküs köklerine ve medial kollateral ve lateral kollateral ligaman insersiyo ve orijinlerine enjekte edildi. Son olarak median parapatellar insizyon alanına ve subdermal alana uygulandı. Klasik ağrı yönetiminde ise operasyon sırasında diz içine herhangi bir enjeksiyon ve analjezik kullanılmadı. Postoperatif ölçümlerde turnikenin açıldığı zaman baz alındı.

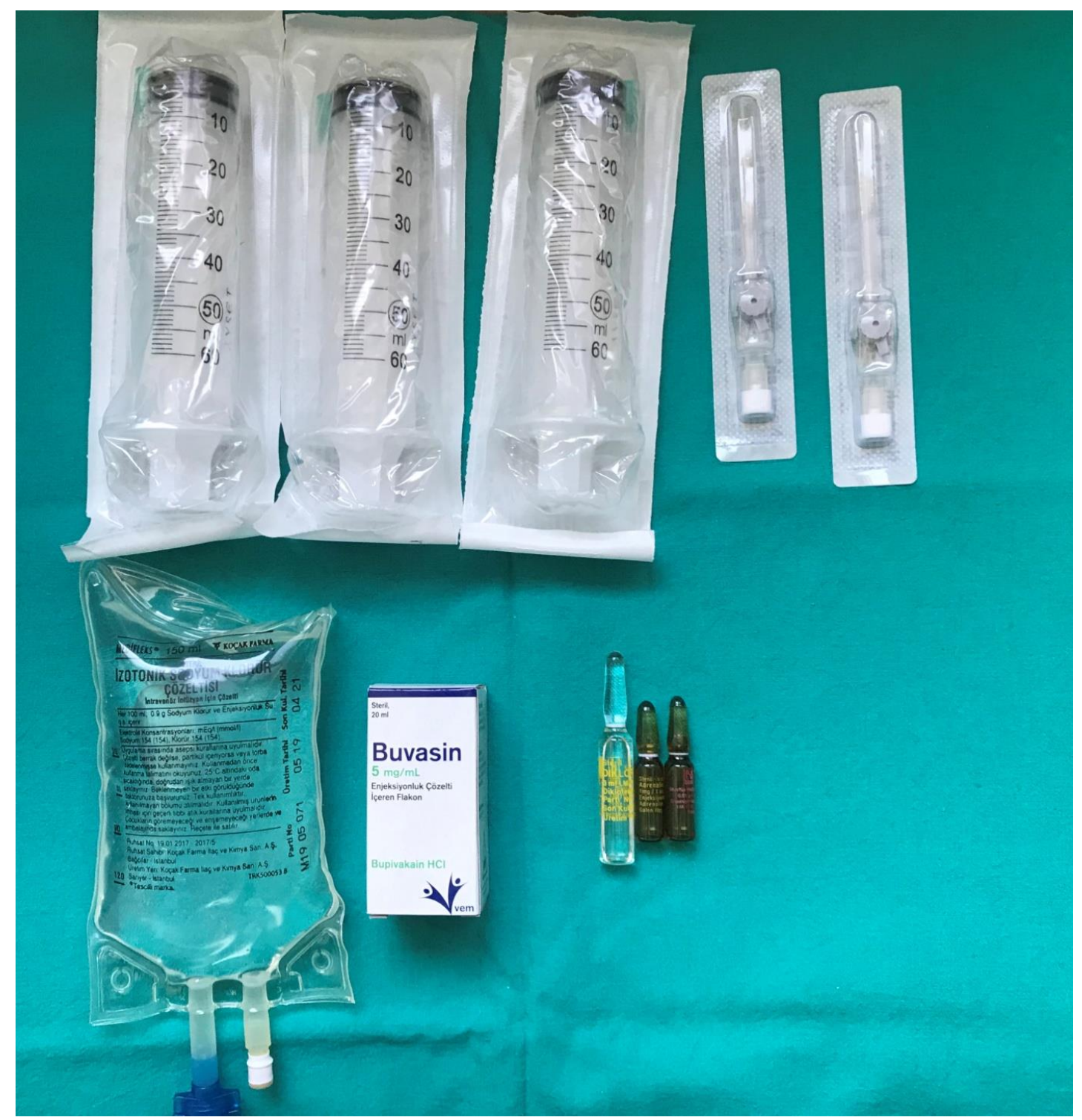

Şekil 1: LPE’ de kullanılan kokteyl içeriği ve kullanılan enjektörler

Her iki grup hastalarında ameliyat sonrası analjezi için gereken oral ve parenteral ilaçlar hastanede kaldığ 1 sürece not alındı.

LPE kullanılan ve kullanılmayan hastalar; yaş, cinsiyet, postoperatif eklem hareket açıklıkları, Visüel Analog Skala (VAS) skorları, komplikasyon, vücut-kitle indeksi, yatış süreleri, yürüteç bırakma, kan transfüzyonu ve bulantı, kusma varlığ 1 kayıt altına alınarak karşılaştırıldı.

Hastaların VAS Skorları; preoperatif, 6. Saat ,12. Saat , 24. Saat, 36. Saat, 15. Gün ve 30. Gün kontrol edildi. Hastaların hastanede yatıs sürelerinde ise; destekle rahat yürüyebilmesi, VAS skorunun 3 ün altında olması ve oral analjezikle kontrol edilebilmesi, cerrahi komplikasyonu olmaması dikkate alındı. 
Eklem hareket açıklıkları gonyometre ile 6. Saat ,12. Saat , 24. Saat , 36. Saat , 15. Gün ve 30. Gün ölçüldü.

Tüm hastalara aynı cerrahi ekip ile aynı cerrahi teknik ile ve spinal anestezi altında diz artroplastisi uygulandı. Hiçbir hastaya epidural anestezi ve katater takılmadı. Yazılı hasta onamı ameliyat öncesi alındı. Hastalar yatağına geldikten sonra soğuk uygulama ve elevasyon ile izlendi. Postoperatif dönemde hemowak drendeki kanama miktarı not edildi. 1. Gün tüm hastaların hemowak drenleri çekildi ve CPM (Continiued Passive Motion) cihazına bağlandı. Ardından fizyoterapist gonyometre ile fleksiyon ve ekstansiyon miktarını ölçerek not aldı. Daha sonra hastalar yürüteç yardımı ile tolere edebildikleri kadar yürütüldü. Hastaların yatış süresince CPM cihazı ve yürümeleri fizyoterapist eşliğinde yapıldı ve yazılı olarak not alındi.

\subsection{Cerrahi teknik}

Tüm hastalar pnömatik turnike $300 \mathrm{~mm} \mathrm{Hg}$ de, supin pozisyonda median parapatellar insizyon ile girildi. Femoral ve tibial kesiler yapıldıktan ve saha bol serum fizyolojik ile yıkandıktan sonra periartiküler enjeksiyona geçildi. Önce kemik kesileri etrafındaki periosta hareketli ve geri çekilerek enjekte edildi. Daha sonra mednisküslerin kesildiği kapsüler bölge ve lateral ve medial kollateral ligamanlara enjekte edildi. Ardından parapatellar insizyon kenarlarına ve ciltaltı dokulara uygulandı. Periartiküler enjeksiyon sonrası artroplasti komponentleri yerleştirildi ve sement donduktan sonra dokular anatomisine uygun olarak kapatild1.

\section{Bulgular}

Çalışmada 92 kadın hasta , 32 erkek hasta bulunmakta ve yaş ortalaması 67 (45-94) dü. Olguların LPE kullanımına göre yaş, cinsiyet, postoperatif komplikasyon, vücut-kitle indeksi, yatış süreleri, yürüteç bırakma, kan transfüzyonu ve bulantı,kusma varlığı oranları dağılımı incelendiğinde gruplar arasında istatistiksel olarak anlamlı fark bulunmadı $(\mathrm{p}>0,05)($ tablo 1-2). Fakat LPE kullanan olguların dren, PO Asetam, PO NSAIII ve PO Opioid değerleri LPE kullanmayan olguların değerlerinden istatistiksel olarak anlamlı düşük bulundu $(\mathrm{p}<0,05)$ (tablo 2).

Tablo 1: Olguların LPE kullanımına göre cinsiyet, komplikasyon ve bulantı varlığı oranları dağılımı

\begin{tabular}{|c|c|c|c|c|c|c|c|}
\hline & \multicolumn{4}{|c|}{ LPE KULLANIMI } & \multirow{3}{*}{$\mathbf{X}^{2}$} & \multirow{3}{*}{$\mathbf{p}$} \\
\hline & & \multicolumn{2}{|c|}{$\operatorname{Var}(n=70)$} & \multicolumn{2}{|c|}{ Yok $(n=54)$} & & \\
\hline & & $\mathbf{n}$ & $\%$ & n & $\%$ & & \\
\hline \multirow[t]{2}{*}{ Cinsiyet } & Kadın & 51 & 72,9 & 41 & 75,9 & \multirow{2}{*}{0,150} & \multirow{2}{*}{0,699} \\
\hline & Erkek & 19 & 27,1 & 13 & 24,1 & & \\
\hline \multirow[t]{2}{*}{ Komplikasyon } & Var & 17 & 24,3 & 11 & 20,4 & \multirow{2}{*}{0,267} & \multirow{2}{*}{0,605} \\
\hline & Yok & 53 & 75,7 & 43 & 79,6 & & \\
\hline \multirow[t]{2}{*}{ Bulantı Kusma } & Var & 22 & 31,4 & 10 & 18,5 & \multirow{2}{*}{2,654} & \multirow{2}{*}{0,103} \\
\hline & Yok & 48 & 68,6 & 44 & 81,5 & & \\
\hline
\end{tabular}


Tablo 2: Olguların LPE kullanımlarına göre yaş, BMI (vücut kitle indeksi), yatış süreleri, yürüteç bırakma, kan TX (transfüzyonu) ile postoperastif oral asetaminofen, NSAİ̇ ve opioid değerleri ortalama dağılımı

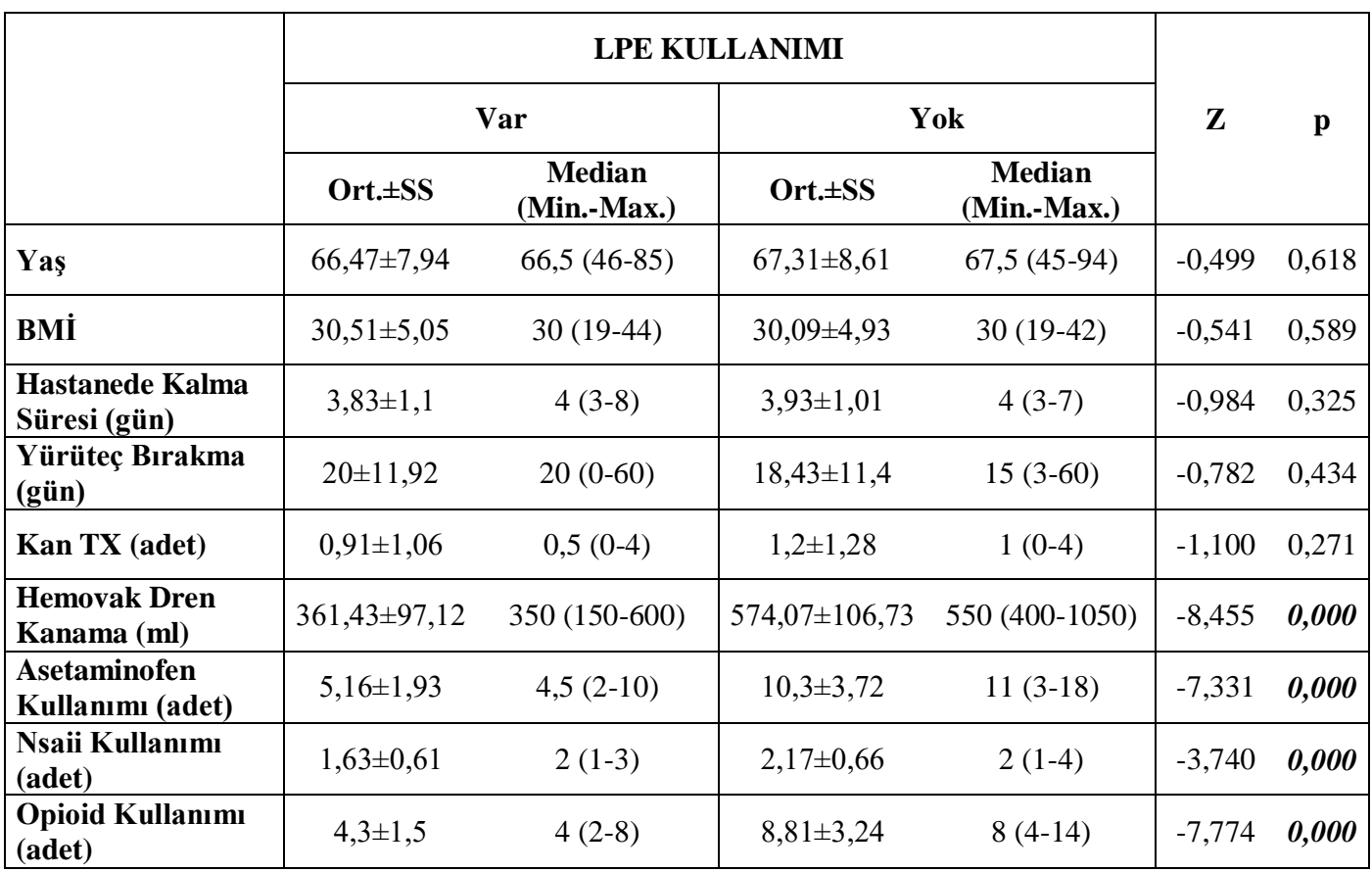

Mann Whitney U analizi

Hastalar postoperatif eklem hareket açıklıklarına göre incelendiğinde; postoperatif 1. Gün ve 15. Gün fleksiyon değerleri LPE kullanılanlarda daha yüksek, postoperatif 1. Gün ve 15. Gün ekstansiyon kısıtlılığı ise daha düşük bulunmuştur. Postoperatif 30. Gün ise eklem hareket açıklıklarında her iki grup arasında anlamlı fark bulunamamıştır (tablo 3).

Tablo 3: Olguların LPE kullanımlarına göre preop ve postop fleksiyon ve extansiyon kısıtlılığ1 değerleri ortalama dağılımı

\begin{tabular}{|c|c|c|c|c|c|c|}
\hline & \multicolumn{4}{|c|}{ LPE KULLANIMI } & \multirow{3}{*}{$\mathbf{Z}$} & \multirow{3}{*}{$\mathbf{p}$} \\
\hline & \multicolumn{2}{|c|}{ Var } & \multicolumn{2}{|c|}{ Yok } & & \\
\hline & Ort. \pm SS & $\begin{array}{c}\text { Median } \\
\text { (Min.-Max.) } \\
\end{array}$ & Ort. \pm SS & $\begin{array}{c}\text { Median } \\
\text { (Min.-Max.) } \\
\end{array}$ & & \\
\hline Preop Fleksiyon & $99,07 \pm 20,4$ & $95(30-145)$ & $108,98 \pm 20,98$ & $110(30-145)$ & $-2,961$ & 0,003 \\
\hline Po. 1. Gün Fleksiyon & $69,36 \pm 6,86$ & $70(60-90)$ & $64,44 \pm 4,73$ & $65(60-80)$ & $-4,368$ & 0,000 \\
\hline $\begin{array}{l}\text { Po. 15. Gün } \\
\text { Fleksiyon }\end{array}$ & $92,57 \pm 12,12$ & $90(60-120)$ & $86,67 \pm 14,41$ & $90(30-110)$ & $-2,668$ & 0,008 \\
\hline $\begin{array}{l}\text { Po. 30. Gün } \\
\text { Fleksiyon }\end{array}$ & $95,21 \pm 9,72$ & $90(70-120)$ & $96,3 \pm 16,49$ & $100(30-120)$ & $-1,571$ & 0,116 \\
\hline $\begin{array}{l}\text { Preop Ekstansiyon } \\
\text { Kısıtlılığı. }\end{array}$ & $3,14 \pm 5,85$ & $0(0-30)$ & $5,37 \pm 10,5$ & $0(0-50)$ & $-1,341$ & 0,180 \\
\hline $\begin{array}{l}\text { Po 1. Gün } \\
\text { Ekstansiyon } \\
\text { Kısıtlılığı }\end{array}$ & $1,14 \pm 2,71$ & $0(0-10)$ & $2,78 \pm 4,2$ & $0(0-15)$ & $-2,552$ & 0,011 \\
\hline $\begin{array}{l}\text { Po 15. Gün } \\
\text { Ekstansiyon } \\
\text { Kısıtlılığı } \\
\end{array}$ & $2 \pm 5,86$ & $0(0-35)$ & $2,69 \pm 3,85$ & $0(0-15)$ & $-2,221$ & 0,026 \\
\hline $\begin{array}{l}\text { Po 30. Gün } \\
\text { Ekstansiyon } \\
\text { Kısıtlılığı } \\
\end{array}$ & $1,79 \pm 5,78$ & $0(0-35)$ & $1,6 \pm 2,73$ & $0(0-10)$ & $-1,325$ & 0,185 \\
\hline
\end{tabular}


Operasyon sonrası hastaların ağrı şiddetleri VAS ile incelendiğinde ; LPE kullanılan olguların postoperatif 6. saat, 12. saat, 1. Gün ve 2. gün VAS skorlar1, LPE kullanmayan olguların VAS skorlarından istatistiksel olarak anlamlı düşük bulundu $(\mathrm{p}<0,05)($ tablo4 ). Postoperatif 3. gün, 15. gün ve 30. Gün VAS skorları açısından gruplar arasında istatistiksel olarak anlamlı fark bulunmadı $(\mathrm{p}>0,05)$ (tablo 4).

Tablo 4: Olguların LPE kullanımlarına göre perop ve postop VAS skorları ortalama dağılımı

\begin{tabular}{|c|c|c|c|c|c|c|}
\hline & \multicolumn{4}{|c|}{ LPE KULLANIMI } & \multirow{3}{*}{$\mathrm{Z}$} & \multirow{3}{*}{$\mathrm{p}$} \\
\hline & \multicolumn{2}{|c|}{ Var } & \multicolumn{2}{|c|}{ Yok } & & \\
\hline & Ort. \pm SS & $\begin{array}{c}\text { Median } \\
\text { (Min.-Max.) }\end{array}$ & Ort. \pm SS & $\begin{array}{c}\text { Median } \\
\text { (Min.-Max.) } \\
\end{array}$ & & \\
\hline Perop VAS Skoru & $7,23 \pm 1,64$ & $7(2-10)$ & $7,09 \pm 1,87$ & $7(2-10)$ & $-0,339$ & 0,734 \\
\hline $\begin{array}{l}\text { Postop 6. Saat VAS } \\
\text { Skoru }\end{array}$ & $4,5 \pm 1,28$ & $4(2-8)$ & $7,98 \pm 1,42$ & $8(4-10)$ & $-8,721$ & 0,000 \\
\hline $\begin{array}{l}\text { Postop 12. Saat } \\
\text { VAS Skoru }\end{array}$ & $3,86 \pm 1,04$ & $4(2-6)$ & $7,09 \pm 1,98$ & $8(2-10)$ & $-7,851$ & 0,000 \\
\hline $\begin{array}{l}\text { Pos. 1. Gün VAS } \\
\text { Skoru }\end{array}$ & $3,57 \pm 1,12$ & $4(1-7)$ & $5,91 \pm 1,7$ & $6(1-9)$ & $-7,063$ & 0,000 \\
\hline $\begin{array}{l}\text { Pos. 2. Gün VAS } \\
\text { Skoru }\end{array}$ & $3,84 \pm 0,75$ & $4(2-5)$ & $4,44 \pm 1,66$ & $4(0-9)$ & $-2,637$ & 0,008 \\
\hline $\begin{array}{l}\text { Pos. 3. Gün VAS } \\
\text { Skoru }\end{array}$ & $3,4 \pm 0,89$ & $3(2-8)$ & $3,78 \pm 1,79$ & $4(1-10)$ & $-1,309$ & 0,191 \\
\hline $\begin{array}{l}\text { Pos. 15. Gün VAS } \\
\text { Skoru }\end{array}$ & $2,33 \pm 1,98$ & $2(0-7)$ & $2,91 \pm 1,79$ & $3(0-7)$ & $-1,901$ & 0,057 \\
\hline $\begin{array}{l}\text { Pos. } 30 \text { Gün VAS } \\
\text { Skoru }\end{array}$ & $1,89 \pm 1,84$ & $2(0-7)$ & $1,65 \pm 1,32$ & $2(0-5)$ & $-0,237$ & 0,813 \\
\hline
\end{tabular}

\section{Mann Whitney U analizi}

Hiçbir hastada ciddi kardiak ,nefrotoksik ve gastrointestinal yan etki saptanmadi. LPE yapılan 22 hastada ve yapılmayan 11 hastada hafif düzeyde bulantı izlendi.Hepsi destek tedavisi ile düzeldi. Fakat istatiksel olarak anlamlı bulunmadi. LPE uygulanan 7 hastada ve LPE kullanılmayan 9 hastada yara yerinde yüzeyel hiperemi izlendi. Takiplerde ilerleme olmadı. LPE uygulanmayan 1 hastada karaciğer fonksiyon testlerinde yükseklik izlendi ve yakın takiplerinde geriledi. LPE uygulanan 1 hastada derin ven trombozu izlendi ve 12 hafta enoksaparin tedavisi ile tedavi edildi.

Tablo 5: İki grup arasındaki VAS skoru değişimi

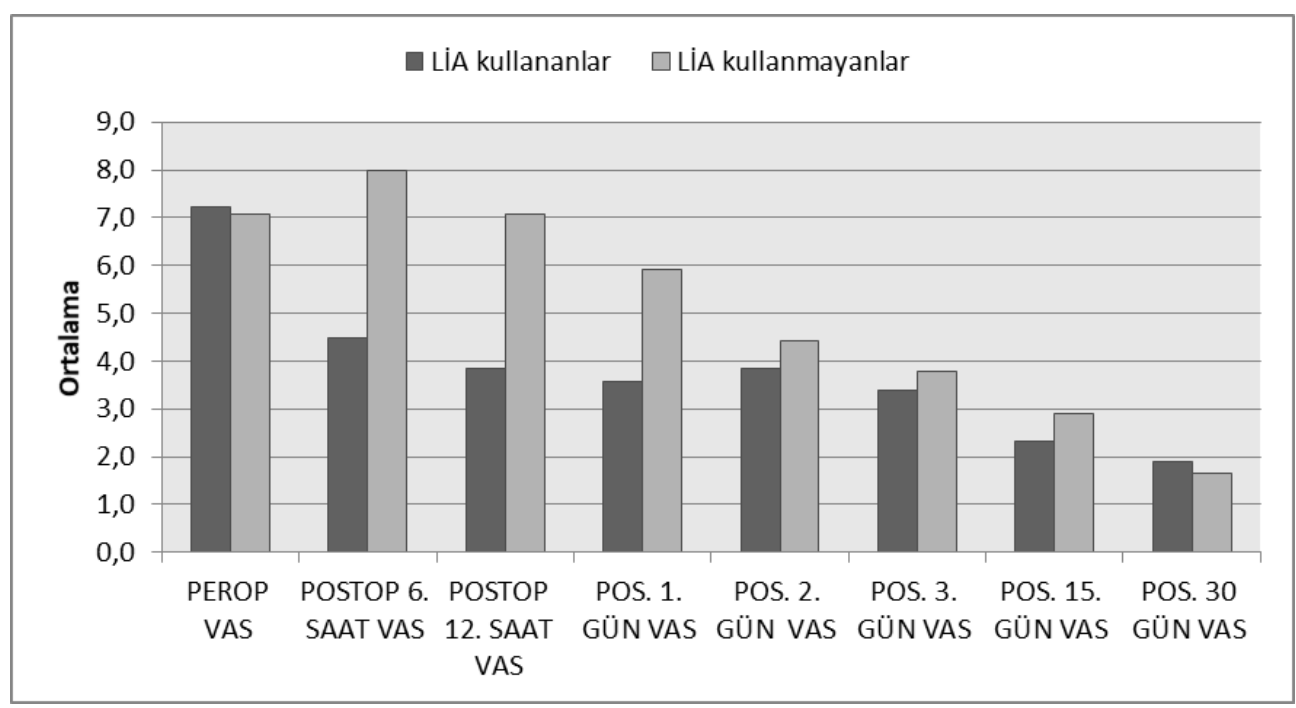




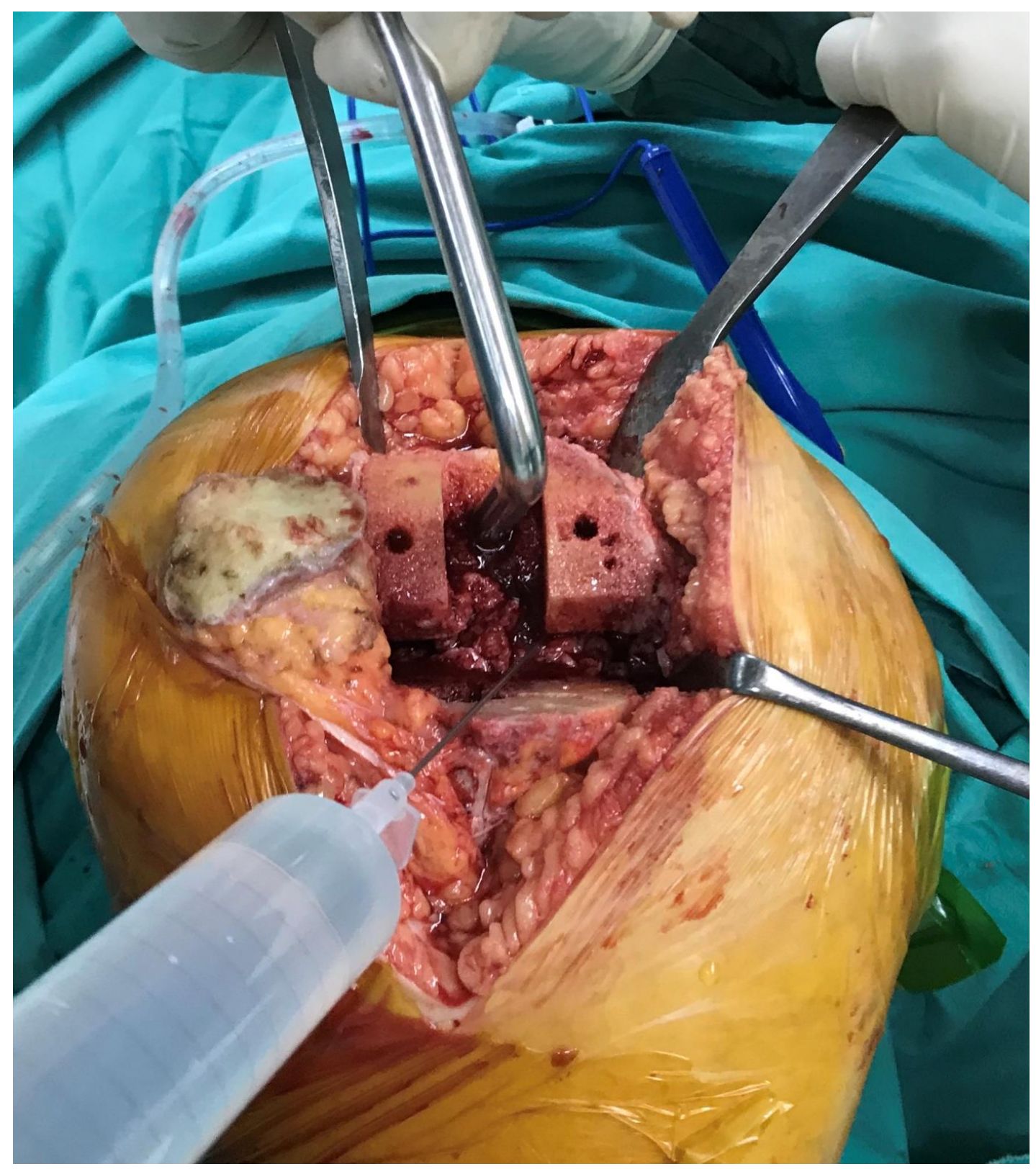

Şekil 2: LPE uygulanırken posterior anatomik yapılara enjeksiyonu 


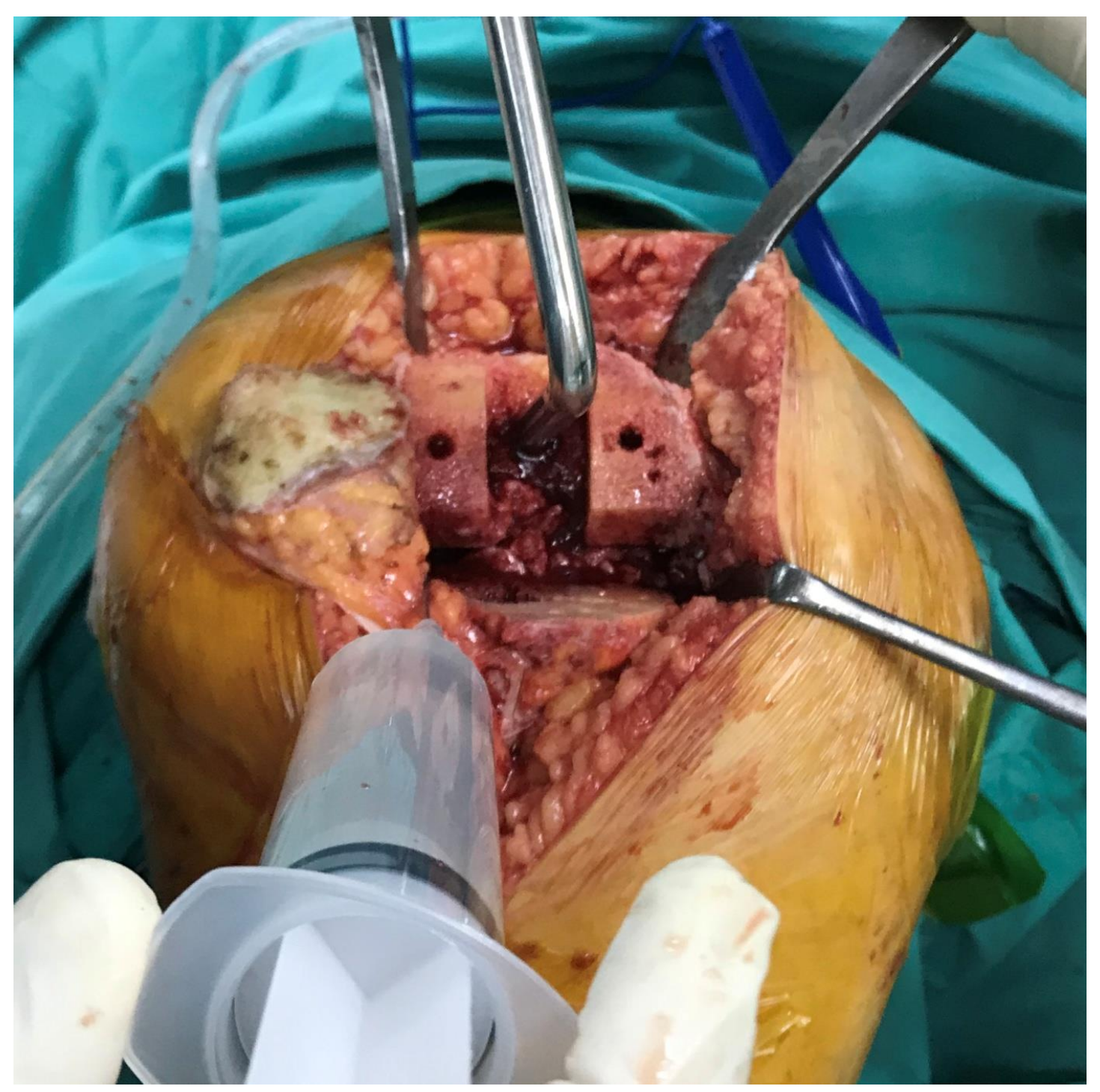

Şekil 3: LPE uygulanırken posterior anatomik yapılara enjeksiyonu 


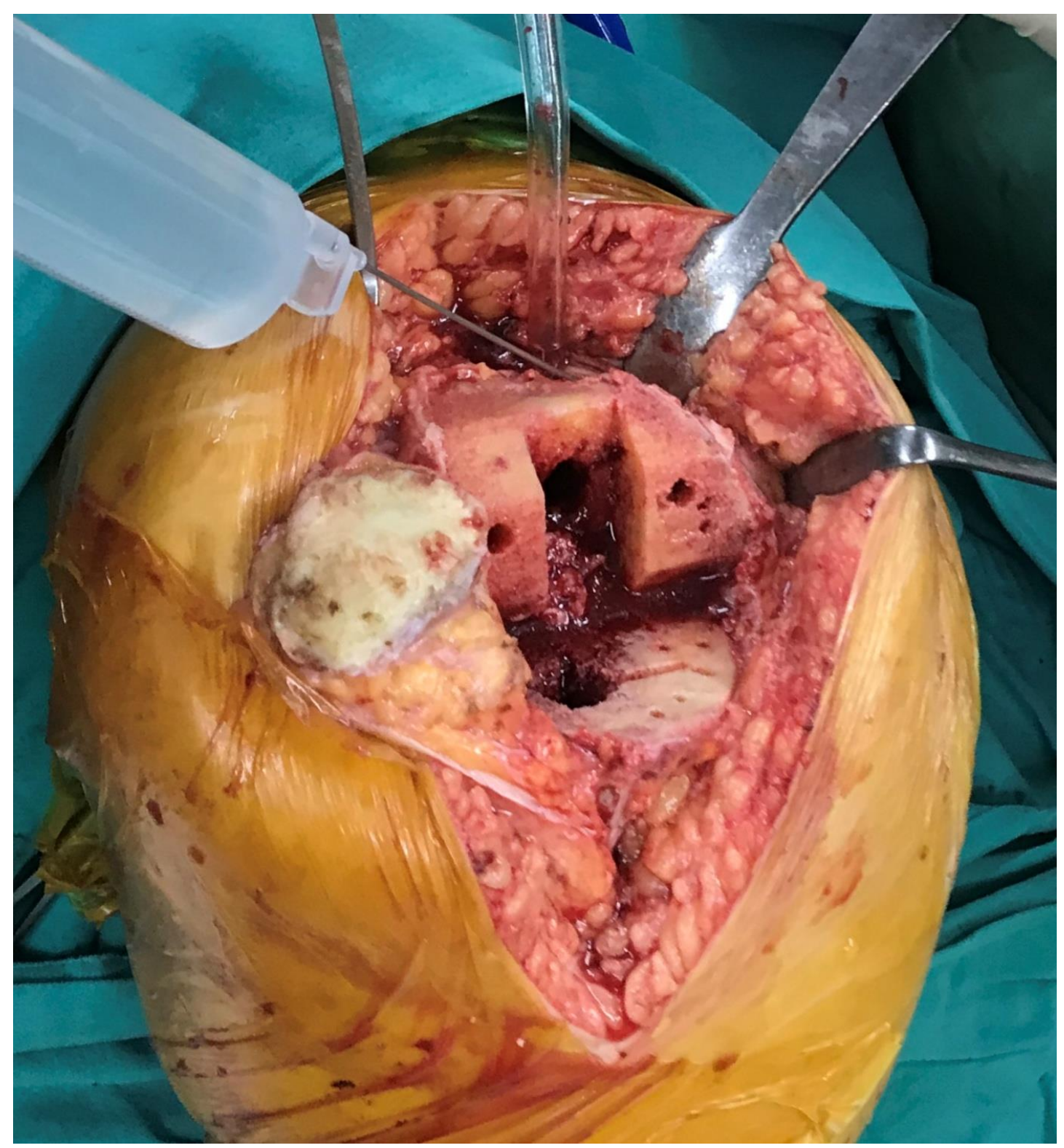

Şekil 4 : LPE uygulanırken anterior anatomik yapılara enjeksiyonu 


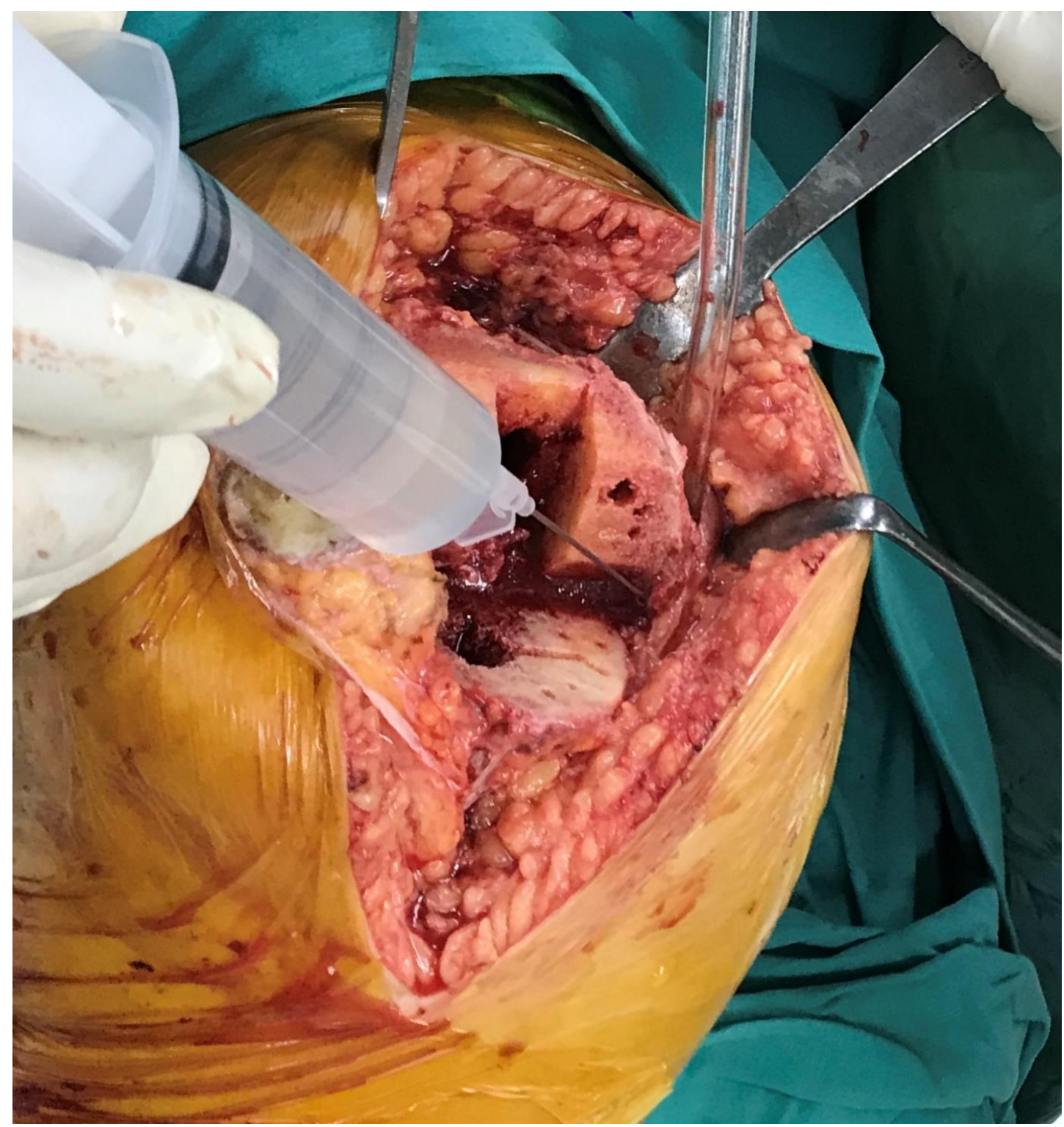

Şekil 5 : LPE uygulanırken medial anatomik yapılara enjeksiyonu 


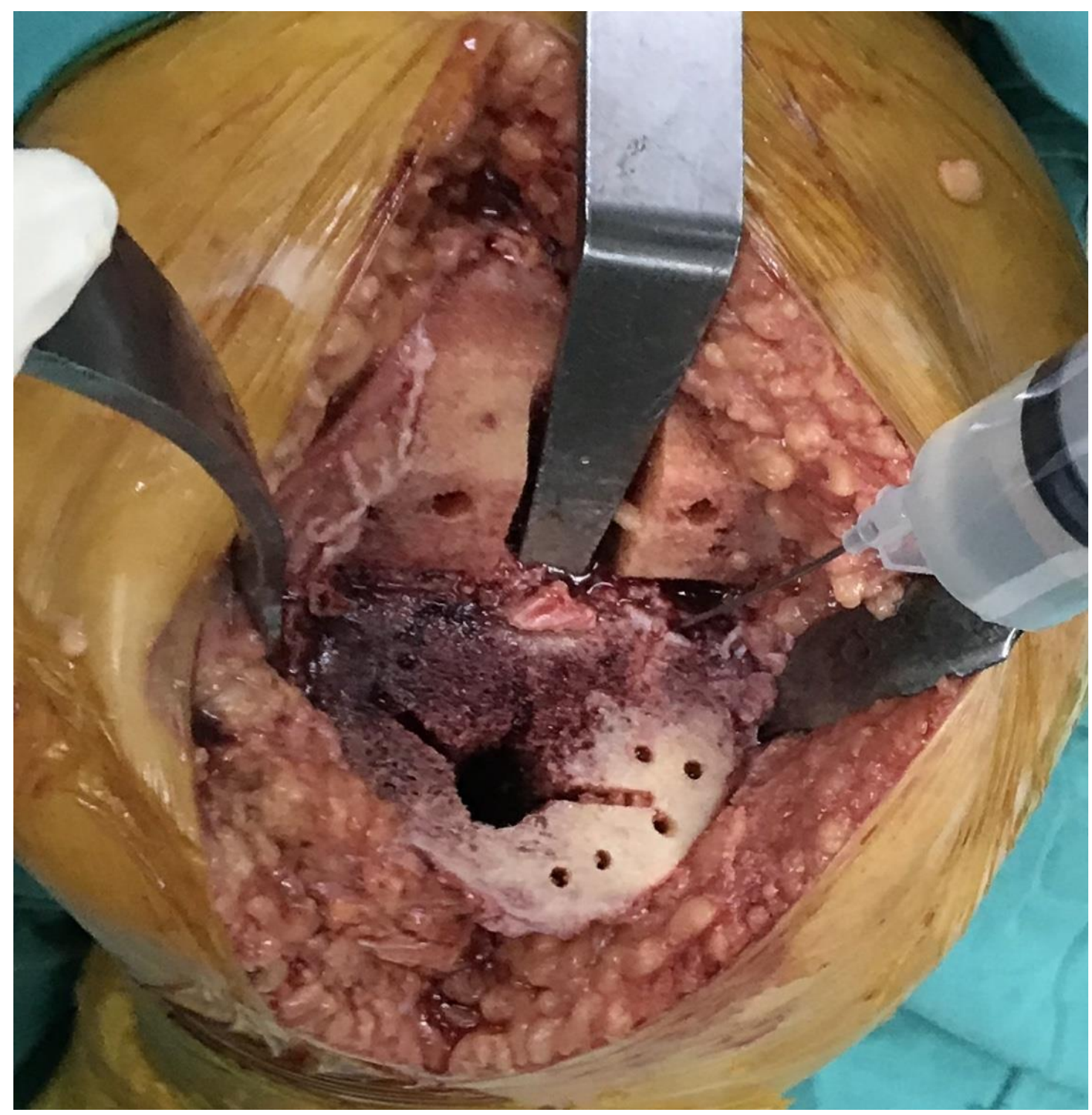

Şekil 6: LPE uygulanırken posterior anatomik yapılara enjeksiyonu

\section{Tartışma}

Ameliyat sonrası erken dönemdeki ağrı; cerrahi bölgedeki doku hasarı sonucu ortaya çıkar ve hem hastayı hem cerrahı yakından ilgilendirir. Elektif cerrahi için ağrının nedeni, başlama zamanı, oluşum yeri ve muhtemel süresi önceden bilinir. Özellikle TDA gibi hem kemiği hem de yumuşak dokuyu içeren bir operasyonda şiddetli ağrı kaçınılmazdır. TDA sonrası erken dönem ağrıyı kesmek için bir çok ağrı yönetimi kullanılmaktadır. Son dönemlerde oldukça popüler olan yöntemlerden biri LPE’dir. Birçok otör tarafından kullanılan LPE'de uygulanan kokteylde farklı ilaç kombinasyonları kullanılmaktadır. Şiddetli postoperatif ağrı, hastanede kalma süresinin uzaması, postoperatif bulantı ve kusmanın artması opioid kullanımının da artmasına yol açmaktadır [4]. Ayrıca, artrofibroz ve azalmış hareket açıklığının postoperatif ağrı derecesi ile yakından ilişkili olduğu gösterilmiştir[5] . Ranawat ve ark.ları kendi merkezlerinde yaptığı çalışmada ; parenteral narkotiklerin neden olduğu komplikasyonların önlendiğinde hastalar operasyonlarından daha fazla memnun olduklarını belirtmişlerdir. Ayrıca; solunum depresyonu, bulant1, kusma, ileus, idrar retansiyonu, hipotansiyon, bradikardi ve bilişsel değişiklikler gibi komplikasyonların azaltılmasıyla operasyonun güvenliğinin arttırılacağını belirtmişlerdir. $\mathrm{Bu}$ nedenlerden dolayı, periartiküler enjeksiyonlu multimodal bir ağrı programının, kalça ve diz artroplastilerinden sonra perioperatif ağrı yönetiminde önemli bir yeri olduğunu vurgulamışlardır.

Vendittoli ve ark.[6], LPE kullanımının daha az ağrı, gelişmiş fonksiyonel iyileşme ve hasta memnuniyetine neden olabileceğini göstermiştir. Bununla birlikte Koh ve ark.[7], ameliyat sonrası yakın dönemde ağrı azalmasının anlamlı olduğunu, 48 saat sonra fonksiyonel sonuçlarda veya hasta 
memnuniyetinde iyileşme olmadığını gözlemlemiştir. Şuan için, perioperatif ağrının multimodal tedavisi, ameliyat sonrası persistan ağrının insidansını azaltmada en yaygın yol olmuştur. LPE'nin kısıtlı bir etkiye sahip olup ve hastaneden taburcu edildikten sonra diğer tedavilerin yerini almadığ belirtilmiştir.[7][8][9]. Yine de, LPE oral veya intravenöz opioidlerin kullanımından kaynaklanan komplikasyonlar olmadan analjezik etkiyi arttırmada önemli sonuçlar göstermiştir.

Periartiküler enjeksiyon için kullanılan kokteyllerde bazı yazarlar ağrıyı azaltmak amacıyla steroid de kullanmıştır. Sean ve ark.larının çalışmasında steroid kullanılan grupta kullanılmayan gruba göre ağrı anlamlı olarak azalmıştır ( $\mathrm{p}$ <.007)[10]. Yue ve ark.larına göre ise ameliyat sonrası ağrıda steroid kullanımının önemi yoktur [11] . Yue ve ark.larını destekleyen başka çalışmalar da mevcuttur[12][13].Biz kokteylimizde steroid ve türevi kullanmadık. Çünkü steroid ve türevlerinin oluşturacağ güçlü antiinflamatuar etkinin doku iyileşmesini olumsuz etkileyebileceğini, enfeksiyon oranını artıracağını ve az da olsa sistemik yan etkileri olabileceğini düşündük. Burada irdelenmesi gereken önemli bir noktada ilaç kombinasyonlarının sayısı, dozları ve olumlu olumsuz etkilerinin ne olacağı konusudur. Bizim kokteylde kullanılan ilaç sayısı da literatürdeki diğer kokteyllerden az olmakla birlikte sonuçlarımız postoperatif analjezi ve kanama kontrolünde en az diğer kokteyller kadar etkili olduğunu göstermiştir. Böylece ilaçların olası yan etkilerinden kaçınılmıştır.

Badner ve arkadaşlarının çalışmasında eklem içi kokteylde morfin kullanılmasının tek başına antiinflamatuar ilaç kullanılan kokteyllere belirgin üstün olmadığını bildirmişlerdir[14]. Buna karşı olarak Stein ve arkadaşları morfinin kokteyle eklenmesinin ameliyat sonrası ağrı kontrolünde olumlu sonuçlar ortaya koyduğunu göstermektedir[15]. Bu noktada bizde Stein ve arkadaşlarıyla aynı görüşteyiz ve LPE ' de antiinflamatuar ilaç ve morfinin daha etkili ağrı kontrolünü sağladığını düşünmekteyiz.

TDA ameliyatı sonrası erken dönem ağrı için kullanılan yöntemlerden kalıcı epidural katater uygulaması yaygın kullanılsada ilaçların yan etki insidansı göreceli olarak lokal uygulamalara göre daha dezavantajlıdır. Periartiküler enjeksiyon ve femoral kanal bloğunun karşılaştırıldığı prospektif çalışmada Íshida ve ark.ları; TDA'dan sonra, LPE 'nin analjezik etkisi ile CFNB'den daha erken fonksiyonel iyileşmeyi indüklediğini göstermiştir[16].

Bu çalışmanın en önemli kısıtlılı̆̆ı geriye dönük kohort çalışması oalrak yapılmasıdır. Bunun yanında çalışmanın güçlü yanı kontrol grubunun olması ve sadece total diz artroplasti hastalarından oluşan 124 hasta ve 124 dizi içermesidir.

TDA sonrası erken dönemde ortaya çıkan ağrı; hastanede kalma süresi, hasta rehabilitasyonu ve hasta memnuniyetini olumsuz etkilemektedir[3]. Opiat bazlı ağrı ilaçlarının postoperatif ağrıyı kontrol etmede etkili olduğu gösterilmiş olsa da, sürekli kullanımı ameliyat sonrası ileus[17][18], hipotansiyon [19] ve bağımlılığa[20] yol açabilir. Bu yüzden TDA sonrası erken dönem ağrıyı kesmek için alternatif yollara gidilmiştir . LPE de bu yollardan en önemlilerindendir . Bu çalışmamızda kullandığımız kokteyl ile ilk 48 saat VAS skoru, eklem hareket açıklığı , kanama miktarı ve oral yada parenteral ilaç kullanımı açısından sonuçların oldukça avantajlı olduğunu bulduk. Her ne kadar konvansiyonel ağrı yöntemi ile erken dönemdeki diz hareket açıklığı olumsuz etkilense de orta dönem diz hareket açıklığ1 her iki gruptada aynı bulunmuştur. Çalışmamızda iki grup arasında anlamlı fark çıkmasa da bazı hastalarda belirgin kas atrofisi, eklem sertlikleri ve kalıcı hareket kısıtlılığı gibi olumsuz uzun dönem sonuçlara rastlamadığımızı belirtmek isteriz. Bu anlamda LPE’nin düşük komplikasyon riskinide göz önüne alarak hastalara rutin oalrak kullanılmasını önermekteyiz.

\section{Sonuç}

Çalışmamızda kullandığımız kokteylin içeriğindeki ilaç sayısı literatürdeki benzer çalışmalara kıyasla az olmakla birlikte etkinliği diğer çalışmalarla benzer ve anlamlı olarak bulunmuştur. Sonuç olarak lokal periartiküler enjeksiyon total diz artroplastisi sonrası erken rehabilitasyon, ağrı kontrolü ve kanama kontrolü için oldukça etkili ve uygulanabilir bir yöntemdir.

\section{Kaynaklar}

[1] Jones CA, Pohar S. Health-related quality of life after total joint arthroplasty: a scoping review. Clin. Geriatr. Med. 2012;28:395-429.

[2] Fu H, Wang J, Zhang W, et al. Potential superiority of periarticular injection in analgesic effect and early mobilization ability over femoral nerve block following total knee arthroplasty. Knee Surg. Sports Traumatol. Arthrosc. 2017;25:291-298. 
[3] Carli F, Clemente A, Asenjo JF, et al. Analgesia and functional outcome after total knee arthroplasty: periarticular infiltration vs continuous femoral nerve block. Br. J. Anaesth. 2010;105:185-195.

[4] Indelli PF, Grant SA, Nielsen K, et al. Regional anesthesia in hip surgery. Clin. Orthop. Relat. Res. 2005;441:250-255.

[5] Ranawat CS, Ranawat AS, Mehta A. Total knee arthroplasty rehabilitation protocol: what makes the difference? J. Arthroplasty. 2003;18:27-30.

[6] Vendittoli P-A, Makinen P, Drolet P, et al. A multimodal analgesia protocol for total knee arthroplasty. A randomized, controlled study. J. Bone Joint Surg. Am. 2006;88:282-289.

[7] Koh IJ, Kang YG, Chang CB, et al. Additional pain relieving effect of intraoperative periarticular injections after simultaneous bilateral TKA: a randomized, controlled study. Knee Surg. Sports Traumatol. Arthrosc. 2010;18:916-922.

[8] Webb CAJ, Mariano ER. Best multimodal analgesic protocol for total knee arthroplasty. Pain Manag. 2015;5:185-196.

[9] Parvataneni HK, Shah VP, Howard H, et al. Controlling pain after total hip and knee arthroplasty using a multimodal protocol with local periarticular injections: a prospective randomized study. J. Arthroplasty. 2007;22:33-38.

[10] Sean VWT, Chin PL, Chia SL, et al. Single-dose periarticular steroid infiltration for pain management in total knee arthroplasty: a prospective, double-blind, randomised controlled trial. Singapore Med. J. 2011;52:19-23.

[11] Yue D, Wang B, Liu K, et al. Efficacy of multimodal cocktail periarticular injection with or without steroid in total knee arthroplasty. Chin. Med. J. (Engl). 2013;126:3851-3855.

[12] Christensen CP, Jacobs CA, Jennings HR. Effect of periarticular corticosteroid injections during total knee arthroplasty. A double-blind randomized trial. J. Bone Joint Surg. Am. 2009;91:25502555 .

[13] Chia SK, Wernecke GC, Harris IA, et al. Peri-articular steroid injection in total knee arthroplasty: a prospective, double blinded, randomized controlled trial. J. Arthroplasty. 2013;28:620-623.

[14] Badner NH, Bourne RB, Rorabeck CH, et al. Intra-articular injection of bupivacaine in kneereplacement operations. Results of use for analgesia and for preemptive blockade. J. Bone Joint Surg. Am. 1996;78:734-738.

[15] Stein C, Comisel K, Haimerl E, et al. Analgesic effect of intraarticular morphine after arthroscopic knee surgery. N. Engl. J. Med. 1991;325:1123-1126.

[16] Ishida K, Shibanuma N, Matsumoto T, et al. Periarticular multimodal drug injection improves post-operative pain and functional recovery after total knee arthroplasty. J. Orthop. Sci. 2016;21:178-183.

[17] Camilleri M. Opioid-induced constipation: challenges and therapeutic opportunities. Am. J. Gastroenterol. 2011;106:835-842; quiz 843.

[18] Holzer P. New approaches to the treatment of opioid-induced constipation. Eur. Rev. Med. Pharmacol. Sci. 2008;12 Suppl 1:119-127. 
[19] Mahinda TB, Lovell BM, Taylor BK. Morphine-induced analgesia, hypotension, and bradycardia are enhanced in hypertensive rats. Anesth. Analg. 2004;98:1698-1704, table of contents.

[20] Schwarzkopf R, Drexler M, Ma MW, et al. Is There a Benefit for Liposomal Bupivacaine Compared to a Traditional Periarticular Injection in Total Knee Arthroplasty Patients With a History of Chronic Opioid Use? J. Arthroplasty. 2016;31:1702-1705. 